\title{
Conservation education in threatened species management in Africa
}

\author{
YAA NTIAMOA-BAIDU
}

\begin{abstract}
Summary
The issues that need to be addressed in conservation education programmes aimed at saving threatened species in Africa are discussed. Elements considered as crucial for the success of such programmes include a clear definition of the problem, identification of the target groups, definition of appropriate messages for each group, and development of suitable strategies for dissemination. The advantages of using local people to implement education programmes are outlined. A system for monitoring and evaluation is essential for the assessment of the success of programmes and provides opportunities for improvement, re-definition of priorities and reallocation of resources.
\end{abstract}

\section{Introduction}

Most of the factors which threaten the survival of many wild animal species today result from exploitative human activities that interfere with nature's self-regulatory systems. Often the people involved are ignorant of the status of the species and the effects of their actions. Until such people understand these issues, they are not likely to accept that there is a need for a change in their attitudes and actions. It is therefore imperative that threatened species management programmes incorporate a conservation education component to sensitize people to the threats facing a species, the need for its protection, and the actions required to ensure its survival.

Very often, scientific research is given strong emphasis in planning threatened species management projects, while conservation education is accorded low priority and regarded as a minor component, to be done if time permits. Often, such education is delegated to project managers who are mostly research scientists. Such people may either not have expertise in conservation education, or their other commitments limit the time they can devote to it.

The role of the research scientists is to identify the factors threatening the survival of the species and develop measures for alleviating those threats. The threats must then be explained to the people (whose actions affect the threatened species) in a way that can be easily appreciated and understood. The first commitment therefore is to ensure that a conservation education unit is established as an integral component of any threatened species management project, and that provision is made in the project budget for the training of conservation educationists.

This paper outlines the essential components of conservation education programmes in threatened species management in Africa. Illustrations are 
drawn from the experiences of the "Save the Seashore Birds Project-Ghana" (hereafter SSBP-G), a joint venture between the Ghana government, the Royal Society for the Protection of Birds (RSPB) and the International Council for Bird Preservation (ICBP, now BirdLife International), which aims at saving the Roseate Tern Sterna dougallii as well as other seashore birds and their coastal wetland habitats.

\section{Essential components in a conservation education programme}

The goal of an education programme should be the production of a change in people's attitudes and perceptions, leading to specific actions that protect the species needing conservation. Six steps are considered crucial to the success of any conservation education programme: (1) definition of the problem; (2) identification of the target groups for education; (3) definition of the conservation message; (4) development of strategies for disseminating the message; (5) development of methods for implementing the education programme; (6) development of a system for monitoring, evaluation, feedback and revision.

\section{Problem identification}

Identification of the conservation problem is straightforward in the case of threatened species: the population is declining and the species is likely to become extinct if nothing is done to eliminate the threats. What is more difficult is the identification of the threats and the factors that are causing the decline. The focus for the SSBP-G was the Roseate Tern. By the mid-1980s the Irish and British breeding population of this species had declined from about 2,500 pairs to under 500 pairs over a 20-year period (Avery 1987). The threats identified included habitat destruction, competition with other seabirds on the breeding grounds and destruction of terns through trapping on the wintering grounds (Everett et al. 1987).

\section{Identification of target groups}

Five main target groups are identifiable in a conservation education programme: (a) policy-makers; (b) the general public; (c) specific groups whose activities directly or indirectly affect the wildlife resource; (d) groups whose involvement in or contribution to the education programme is considered a key factor to the success of the programme; (e) project managers, project staff and relevant conservation officers.

Policy- and decision-makers (target group a) need to establish supportive policies and avoid decisions that can have adverse effects on the species being protected. Recommendations for specific actions that they are expected to take must be followed up to confirm their implementation. This is particularly important in African countries where, because of numerous competing national needs and limited resources, conservation tends to be given low priority.

Through the advice of the SSBP-G, the Ghana government took a number of actions to protect seashore birds and their wetland habitats. These included the enactment of a law - Wildlife Conservation (Amendments) Regulation, PNDC 
Law 1357, January 1988 - which placed all terns on Ghana's list of wholly protected species; and the ratification of the Bonn and Ramsar Conventions. The establishment of the law gave legal backing to the project's efforts to stop tern-trapping, while the ratification of the conventions made it obligatory for the government to take specific actions. Once a government takes this initial action, its attention can repeatedly be drawn to its obligations and duties to the international community.

The general public (target group b) needs to be educated to increase its awareness and appreciation of the problem, and to gain its support for the various conservation activities.

The specific groups (c) whose activities maintain or deplete the resource in question must be made aware of their role. In the case of the SSBP-G, the groups whose activities adversely affected the terns were the fishermen and the coastal communities who shared the fisheries resources with the terns and whose fishing activities could affect the terns; and the children who trapped terns.

Groups (d) whose involvement was considered paramount for the success of the SSBP-G included school teachers, village heads, elders and chiefs, media personnel and law enforcement agencies such as the police, army and local political groups.

It is often mistakenly assumed that project staff (target group e) understand the problems and the objectives of the project. In fact, project staff must be trained in community relations if they are to be able to interact with and educate communities about the project, its values and possible benefits to them. Project staff need to develop a good relationship with the local people, and respect the traditions and traditional knowledge of those people. In a recent survey of local people's perceptions of forest national parks in Ghana I found that, although one park had been in existence for 18 years, the communities in its immediate vicinity had no knowledge that it was set aside as a reserve, or what benefits they would gain from the protection of the wild animals in the area. They saw the wildlife officers as "government officers who were there to arrest and harass people who entered the park", not as people who were there to help them protect their wildlife resources for their own benefit.

The priority given to these five groups will vary from project to project. Children were considered to be the priority group in the SSBP-G because of their involvement in tern-trapping. It is also easier to change the habits and attitudes of a child than an adult; and once a child becomes conscious of conservation problems, the chances are that it will grow up sympathetic to the cause of conservation.

\section{Defining the conservation message}

The conventional message in the management of a species in danger of extinction is simple: there is a need to protect the species and its habitat to enhance its chance of survival. This simple message may, however, mean nothing to some local communities. Often they cannot comprehend or recognize why a wild animal should require protection from humans. This is particularly so in the case of species for which the people have no direct use or need. 
The conservation message must be easily comprehensible. Particular efforts should be made to relate the message to concepts that are familiar to the local people, concepts with which they can identify themselves and their needs. A knowledge of the people's traditions and customs is essential. One of the concepts which some communities in Africa find difficult to comprehend is the limited rate of renewability of natural resources. To overcome this problem, I often relate the concept to the tradition adopted in the case of domestic animals where the people never kill reproductive females, to ensure increase in their stocks.

In order to define a message which is likely to be accepted by the local people, a number of issues need to be addressed. (1) What are the people's perceptions of the species: do they see it as beneficial, as a pest, or something to be disliked? (2) What benefits are likely to be derived by the local people from protecting the species? (3) Does the species have any traditional or cultural value, and if so, are there any traditional strategies for protecting it?

If the threatened species is considered beneficial, this and the losses likely to accrue if it is wiped out should be stressed, e.g. terns as indicators of fish shoals (Ntiamoa-Baidu 1991) or storks as indicators of the coming of rain (Isack 1987). Benefits do not necessarily have to be nutritional or economic. Cultural benefits may provide an equally important incentive for protecting a species. In a number of African communities, wild animals have special cultural significance: they may constitute significant parts of ceremonies, symbolize a particular clan, be sacred or be identified with the people's ancestry. For example, the African Grey Parrot Psittacus erithacus is the symbol of the Agona clan of the Akans in Ghana, while the Pied Crow Corvus albus and the Hooded Vulture Necrosyrtes monachus signify the identity of the Asona and the Asakyiri clans respectively. Such animals are protected and it is a taboo for members of the clan to destroy or in some cases even to touch these animals.

If the species is considered a pest, or if the people have an aversion to it as a result of traditional beliefs and superstitions, there is the additional problem of changing attitudes. To do this, one has to find some positive aspects which can be highlighted and used. For example, owls are considered as witches and are associated with death by many African communities (Isack 1987, Ntiamoa-Baidu 1989), but they are also very beneficial as control agents for pest species such as rats and mice.

If people depend on the species for food or income, sustainable utilization, rather than total protection, must be advocated. In a number of African communities, the concept of sustainability, "exploiting a resource in such a way that it will always be available", is deeply engrained in traditional beliefs, and features in proverbs and folklore. The problem arises where circumstances (e.g. population growth, inadequate resources to meet social aspirations and poverty) make it impossible for the communities to adhere to the principle of sustainable use. In such a situation, protection can never be achieved without addressing the basic factors which lead to over-exploitation.

If the species requires full protection and a total ban must be advocated for a resource on which a community depends, alternatives must be offered. For example, the main reason for tern-trapping in Ghana was for fun and sport. This indicated an obvious interest in the birds, albeit a destructive one. The strategy of the SSBP-G was to convert this interest to a positive one by offering 
the children the opportunity to enjoy the birds through birdwatching and learning about birds. This was done by the establishment of wildlife clubs. The use of binoculars and telescopes for birdwatching and the story of migration were some of the things which fascinated the children most.

A major problem arises when people cannot perceive that the rate at which they are exploiting a resource is not sustainable, and when they instead attribute the decrease in availability to other factors. In the study of local perceptions of forest national parks in Ghana, all the people interviewed agreed that there had been a drastic reduction in bushmeat availability. A number of them, however, attributed the scarcity to restrictions on hunting rather than a real decrease in wild animal populations. In such cases, concrete evidence of the decline is required to convince the people of the reality of the situation.

The message has to be modified to suit each target group. A politician is more likely to be persuaded by the economic benefits of conservation actions, whereas local communities may be more concerned about the food value of the resource.

\section{Strategies for disseminating the message}

Two main strategies have been used for disseminating conservation messages: public awareness campaigns and education programmes. Public awareness campaigns involve the use of the media (radio, television, newspapers) and the production and distribution of publicity materials (posters, badges, pens, pencils, stickers, etc.). Education programmes involve personal visits to communities, talks, film- or slide-shows, plays, and the production and distribution of educational materials (e.g. pamphlets, booklets, newsletters and magazines). One area which remains to be developed is the use of local traditions, plays, songs, folklore, etc., in conservation education.

Wildlife clubs can play a major role in creating interest in wildlife among school-age children and the general public. The strategy used by the SSBP-G was to visit a school and identify an interested teacher, who was then encouraged to start a club in the school. The club registered with the project on payment of registration and membership fees. Although the membership fee was only a small sum of money, it generated a sense of commitment. In return for this, the SSBP-G provided members with a membership card, badge, educational materials and copies of the club magazine. The SSBP-G also assisted with the organization of field-trips and film-shows by providing technical knowledge and films; and produced club T-shirts which members bought. We found that the club badges and T-shirts were a real source of pride for the children and a very effective incentive for them to want to join the clubs.

The choice of a strategy depends on the circumstances. For example, in illiterate communities personal visits and film-shows (possibly with interpretation into the local dialect) are likely to be more effective than posters and other reading materials.

\section{Methods for implementing the education programme}

Training is an important basic element in the implementation of most programmes. Training for conservation education involves the development of 
specialized skills to communicate the conservation message and to evoke changes in the attitudes of the target group. Training needs must be clearly defined, and training should stress communication skills and an appreciation of the role of local communities.

Efforts should be made to train local people. This is important because people can relate more easily to one of their own than to a foreigner. The foreigner, no matter how well informed, can never be seen as someone who understands the situation fully. African people listen to a foreigner advocating protection for local wildlife but they see the foreigner as someone who does not have to live with what he preaches. They are likely to ignore whatever he says as soon as he departs. Numerous cases exist of projects in Africa, initiated and developed with foreign expertise, where the involvement of local people as educators was minimal. No provision was made for training and the projects died with the departure of the expatriates. One of the keys to the success of the SSBP-G was recognition of this aspect at the onset of the project. Provisions were made by the funding agencies (RSPB and ICBP) for both formal and informal training of Ghanaian nationals, who now carry out the project's activities.

Apart from the project staff, a number of people, including the wildlife club leaders, have benefited from the SSBP-G's training workshops. Most of the leaders knew very little about wildlife and had to be trained. Subject areas covered in the workshops included wildlife ecology, with particular reference to interrelationships between man and wildlife; threats to wild animals and their habitat resulting from man's activities; fund-raising; and the development of projects and activities to sustain members' interest. The club leaders' workshops have been very effective in generating interest and enthusiasm and in providing a forum for the exchange of ideas.

Wildlife camps and rallies are organized for club members. These increase the children's knowledge and promote exchange of ideas and interactions between children of diverse backgrounds. An important offshoot of this is that the older members become involved in leadership and training of the younger ones. Club members in teacher training colleges take responsibility for developing clubs in primary schools within their area.

Another effective tool for programme implementation is the involvement of existing local and traditional groups and institutions. An advisory committee was set up during the initial stages of the SSBP-G, consisting of representatives of all the institutions whose activities affected shorebird conservation. It was very effective in publicizing the project and its objectives among the relevant agencies. For example, representation of the Ghana Canoe Fishermen Council on the committee led to meetings of their members at both national and local levels, and in a number of villages the fishermen took it upon themselves to stop the children from trapping terns (Ntiamoa-Baidu 1990).

\section{Monitoring, evaluation, feedback and revision}

Programme monitoring and evaluation is essential for three reasons: (a) it provides a means of measuring success. This is essential for convincing funding agencies that their funds are being used efficiently; (b) it provides the 
opportunity for the programme implementors to assess methodologies and make improvements; and (c) it provides opportunities for re-definition of priorities and reallocation of resources as necessary.

The system for monitoring and evaluation must be developed at the beginning of the programme in order to obtain baseline data for comparison in later years. It is unfortunate that, in SSBP-G's education programme, tern-trapping intensity was not measured at the beginning of the project. If this had been done, we could compare current trapping intensity with what it was before the programmes started. This would have provided a direct measure of the success of the programmes. Long-term monitoring of tern-trapping has now been introduced as part of the SSBP-G's regular activities.

Assuming that membership of a conservation society is an indication of commitment or willingness to do something for conservation, the growth in conservation societies, e.g. wildlife clubs, also provides a measure of conservation education efforts. The SSBP-G introduced the idea of wildlife clubs into Ghana and launched the "Wildlife Clubs of Ghana" nationwide in March 1987. At this time there were only two clubs. Within four years, the number of clubs had grown to 84 , with a membership of nearly 4,0oo. (By late 1995 there were 350 clubs with over 12,000 members.)

Changes in people's perceptions and attitudes towards wildlife are not easy to measure. A number of indices provide indirect measurements of such changes. One method used by the SSBP-G was to assess the increase in the public's participation in conservation-related activities, e.g. wildlife essay competitions. In 1986 a national essay competition was organized for school children. No entries were received. A similar competition organized in 1989 (two years after the start of the project's education programmes) attracted 222 entries.

Another index used to assess the interest of the Ghanaian public in conservation issues was the number of news items or articles appearing in the national newspapers. A survey of items reported in the Daily Graphic (Ghana's most popular newspaper) showed an increase from four items on wildlife and related issues per month in 1986 to 30 items per month in 1989 (Ntiamoa-Baidu 1991).

A more direct measure of changes in people's perceptions and attitudes would be through the use of questionnaires. An analysis of the responses to questionnaires designed to assess people's attitudes and perceptions to wildlife and their level of conservation awareness, if administered before the beginning of a conservation education programme, and later, should provide a measure of changes that may have occurred as a result of the education programme.

\section{Conclusion}

Changing people's perceptions and attitudes, particularly in places where these attributes are deeply interwoven with strong cultural influences and traditional beliefs, is not an easy task. It is a slow process, requiring a lot of effort, and donor agencies must be prepared to fund conservation education programmes on long-term basis. The task can only be considered accomplished when the people's perceptions and attitudes have been altered to the extent that they would want to protect their wildlife resources without any external influences. 


\section{References}

Avery, M. (1987) Protection of Sterna dougallii. Royal Society for the Protection of Birds and Irish Wildbird Conservancy contract No. 12.05.87.003832. Unpublished.

Everett, M. J., Hepburn, I. R., Ntiamoa-Baidu, Y. and Thomas, G. J. (1987) Roseate Terns in Britain and West Africa. RSPB Conserv. Rev. 1: 56-58.

Isack, H. A. (1987) The cultural and economic importance of birds among the Boran people of northern Kenya. Pp.89-98 in A. W. Diamond and F. L. Filion, eds. The value of birds. Cambridge, U.K.: International Council for Bird Preservation (Techn. Publ. 6).

Ntiamoa-Baidu, Y. (1989) The owl. Nko [Magazine of the Wildlife Clubs of Ghana] (2)1: 2-3.

Ntiamoa-Baidu, Y. (1990) Coastal wetlands conservation: the Save the Seashore Birds Project-Ghana. Pp.91-95 in A. Kiss, ed. Living with wildlife. World Bank Technical Paper No 130.

Ntiamoa-Baidu, Y. (1991) Species protection as a strategy for conservation action in Africa: the case of the Roseate Tern in Ghana. Pp.169-175 in T. Salathé, ed. Conserving migratory birds. Cambridge, U.K.: International Council for Bird Preservation (Techn. Publ. 12).

YAA NTIAMOA-BAIDU

Zoology Department, University of Ghana, Legon, Accra, Ghana 